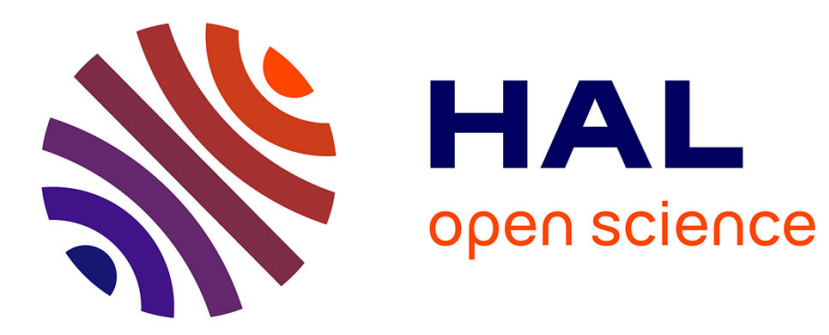

\title{
A prospective study of the bi-directional association between vision loss and depression in the elderly.
}

Isabelle Carrière, Cécile Delcourt, Vincent Daien, Karine Pérès, Catherine Féart, Claudine Berr, Marie-Laure Ancelin, Karen Ritchie

\section{- To cite this version:}

Isabelle Carrière, Cécile Delcourt, Vincent Daien, Karine Pérès, Catherine Féart, et al.. A prospective study of the bi-directional association between vision loss and depression in the elderly.. Journal of Affective Disorders, 2013, 151 (1), pp.164-70. 10.1016/j.jad.2013.05.071 . inserm-00846126

\section{HAL Id: inserm-00846126 https://www.hal.inserm.fr/inserm-00846126}

Submitted on 18 Jul 2013

HAL is a multi-disciplinary open access archive for the deposit and dissemination of scientific research documents, whether they are published or not. The documents may come from teaching and research institutions in France or abroad, or from public or private research centers.
L'archive ouverte pluridisciplinaire HAL, est destinée au dépôt et à la diffusion de documents scientifiques de niveau recherche, publiés ou non, émanant des établissements d'enseignement et de recherche français ou étrangers, des laboratoires publics ou privés. 
A prospective study of the bi-directional association between vision loss and depression in the elderly.

Isabelle Carrière ${ }^{1,2}$, Cécile Delcourt ${ }^{3,4}$, Vincent Daien ${ }^{1,2,5}$, Karine Pérès ${ }^{3,4}$, Catherine Féart ${ }^{3,4}$, Claudine Berr ${ }^{1,2}$, Marie Laure Ancelin ${ }^{1,2}$, Karen Ritchie ${ }^{1,2,6}$

${ }^{1}$ Inserm, U1061, Montpellier, F-34093 France.

${ }^{2}$ University Montpellier I, Montpellier, F-34000 France.

${ }^{3}$ Inserm, ISPED, Centre Inserm U897-Epidemiologie-Biostatistique, F-33000 Bordeaux, France.

${ }^{4}$ Univ. Bordeaux, ISPED, Centre Inserm U897-Epidemiologie-Biostatistique, F-33000 Bordeaux, France.

${ }^{5}$ Department of Ophthalmology, Gui De Chauliac Hospital, Montpellier, France

${ }^{6}$ Faculty of Medicine, Imperial College, St Mary’s Hospital, London, UK

\section{Address for correspondence:}

Dr Isabelle Carrière

Inserm U1061, Neuropsychiatry: epidemiological and clinical research.

Hôpital La Colombière, 39 avenue Charles Flahault, BP 34493,

34093 Montpellier cedex 05, France

Email: isabelle.carriere@inserm.fr

Tel: +33 499614 691, Fax: +33 499614579 


\section{Abstract}

\section{Background:}

Increasing visual impairment (VI) with age has been associated with mental health problems but the question of temporal direction and reverse causality has not been addressed previously. Our objective was to prospectively examine the bi-directional association of VI and visual function (VF) loss with depressive symptoms in the elderly.

\section{Methods:}

The cohort comprised 4216 participants (40.2\% men) aged 65 and over with 10 years of follow-up. Near VI was defined using measured usual-corrected binocular acuity while distance VF was selfdeclared. Participants having a major depressive episode or a Center for Epidemiologic Studies Depression Scale score $\geq 16$ were classified as having depressive symptomatology. Longitudinal analyses used mixed logistic models for repeated evaluations.

\section{Results:}

After adjustment for demographic factors, participants with moderate to severe near VI at baseline had increased odds of developing depressive symptomatology (Odds Ratio $[\mathrm{OR}]=1.60 ; 95 \%$ Confidence Interval $[\mathrm{CI}]=1.08-2.38)$, but after multiple adjustments the association fell below the significance level. A 2-year decrease in distance VF was associated with an increased odds of depressive symptomatology during follow-up after multiple adjustments $(\mathrm{OR}=3.03 ; 95 \% \mathrm{CI}=1.75$ 5.23). Baseline depressive symptomatology was not associated with incident near VI but was associated with VF loss after multivariate adjustment $(\mathrm{OR}=1.62 ; 95 \% \mathrm{CI}=1.15-2.28)$.

Limitations: the causes of VI have not been recorded. 


\section{Conclusion:}

The relation of vision loss to onset of depressive symptomatology differs according to near VI or distance VF and declines across time. A reverse strong association was found between baseline depression and incident loss of distance VF suggesting a downward spiral of events.

Key words: visual impairment, visual function, depressive symptoms, aging, longitudinal studies 


\section{Introduction}

Rates of visual impairment in the elderly increase with age and are not only associated with significant functional loss and mortality (Berger and Porell, 2008; Grue et al., 2010; Jacobs et al., 2005; Laitinen et al., 2007) but also engender considerable psychological distress. Visual impairment has been observed notably to lead to an increased sense of loneliness (Heikkinen and Kauppinen, 2004; Jacobs et al., 2005) and increased rates of clinically significant levels of depressive symptomatology. Moreover, it has been shown that elderly persons with visual impairment have increased rates of suicide (Lam et al., 2008); suicide risk being even higher than that for malignant disease (Waern et al., 2002). While blindness due to late stage disease (e.g. agerelated macular degeneration (AMD), diabetic retinopathy, glaucoma) is not reversible, the majority of moderate to severe visual impairments are correctable (cataract surgery or refractive error correction) and even preventable (glaucoma and AMD). Given that depression is also treatable, early targeting and intervention for persons most at risk could have a significant impact on the psychological well-being of elderly populations.

Most population-based studies of the relationship between vision loss and depressive symptoms conducted to date have been cross-sectional (Bernabei et al., 2011; Evans et al., 2007) and therefore have been unable to determine the temporal direction of the associations. Only three longitudinal, elderly population-based studies have been undertaken which have confirmed the association between visual impairment (Tournier et al., 2008) or visual function loss (Brown and Barrett, 2011; Chou, 2008) and subsequent high levels of depressive symptomatology. However these studies did not include the full range of common risk factors for both visual impairment and depressive symptoms (notably diabetes, hypertension, cardiovascular diseases, cognitive impairment, smoking, obesity) which may confound this association, and two of these studies only 
used self-declared non-specific visual function (Brown and Barrett, 2011; Chou, 2008). In addition, no longitudinal study has examined depressive symptomatology as a risk factor for vision loss, although there are several hypothetical reasons for such an association. Firstly, depression has been associated with behaviors which may increase ocular disease risk, such as poor diet, and excessive tobacco consumption (Glynn et al., 2009), decreased likelihood of seeking appropriate specialist care and following clinical recommendations. Secondly, antidepressants, like other psychotropic agents, may have adverse ocular effects (Richa and Yazbek, 2010). Thirdly, a possible direct effect of depression on neurotransmitter dysfunction leading to visual disturbances has also been suggested (Bubl et al., 2009). It is thus possible that vision loss and depressive symptomatology are associated in a bi-directional manner which may produce a downward spiral in which each in turn triggers the other.

The purpose of this study is to use data from a large epidemiological study providing information on a wide range of potential confounding factors in order to examine the bi-directional association of vision loss as evaluated by self-declared distance visual function and measured near visual acuity with depressive symptomatology across a ten-year period. Numbers from this study are sufficient to permit i) the observation of incident elevated depressive symptomatology in the visually-deficient compared to a sub-group without depressive symptomatology at baseline and ii) incidence of vision loss in depressed persons who did not have vision loss at baseline. The study will thus provide one of the most rigorous observations to date of the risk factors implicated in these associations and also address the question of the temporal direction of associations. Moreover, whereas previous large-scale studies have commonly referred to "vision loss" as a single and static entity we have differentiated near visual impairment and distance visual function at baseline from decline over time in the parameters of both near and distance vision. 


\section{METHODS}

\section{Study sample}

Subjects were recruited as part of a multi-site cohort study of community-dwelling persons aged 65 years and over from the electoral rolls of three French cities (Bordeaux, Dijon and Montpellier) between 1999 and 2001 (The 3C Study Group, 2003). The study protocol was approved by the Ethical Committees of the University-Hospitals of Bicêtre and Nîmes (France) and written informed consent was obtained from each participant. A standardized evaluation with a face to face interview and a number of clinical examinations was undertaken in the three study centers at baseline, 2 and 4 years. In the centers of Bordeaux and Montpellier, this follow-up was extended with an examination at 7 and 10 years. Of the 4216 non-demented participants included in these two centers, 432, 400 and 398 have missing follow-up evaluations for depressive symptomatology, near and distance visual impairment, respectively.

For the depression incidence analysis, the sample included 2307 subjects after exclusion of the 1160 subjects with prevalent depressive symptomatology or using antidepressants at inclusion and exclusion of a further 317 due to missing data for at least one baseline adjustment variable. For the near visual impairment incidence analysis, 2760 subjects were included, after exclusion of the 571 subjects with mild to severe visual impairment at baseline and 485 due to missing data on covariates. Finally, the incidence of distance visual function loss was analyzed on 2952 subjects, after exclusion of the 292 subjects with a loss of their visual function at baseline and 574 due to missing data on covariates.

\section{Depressive symptomatology}

The Mini International Neuropsychiatric Interview (MINI) (Sheehan et al., 1998), a standardized 
psychiatric examination which has been validated in the general population, was used at each examination for the diagnosis of current and past major depressive episodes (MDE), according to

Diagnostic and Statistical Manual of Mental Disorders (DSM)-IV criteria. Severity of depressive symptoms was assessed using the 20-item Center for Epidemiologic Studies-Depression scale

(CES-D) (Radloff, 1977). For this analysis, participants were classified with depressive symptomatology if they presented a current MDE or a CES-D score of 16 or over.

Current use of antidepressants was validated by presentation of the prescription or medication to the interviewer, and type of medication was noted according to the World Health Organization's Anatomical Therapeutic Chemical (ATC) classification.

\section{Visual impairment and visual function loss}

The definitions are based on current presenting vision (i.e. using currently available refractive correction, if any) according to the International Classification of Diseases version 10, 2006 update (Pascolini and Mariotti, 2012; World Health Organisation, 2006). Visual impairment and visual function were assessed at baseline and at every follow-up visit. The study examines separately near visual impairment and distance visual function and their respective decline in the two first years of follow-up.

Binocular near visual acuity was measured with the Parinaud scale (a Jaeger-like reading test commonly used by French ophthalmologists), using usual optical correction. Identical cards were used in the two centers and at all-time points with a standardized reading distance of $33 \mathrm{~cm}$. Parinaud scores range from 2 (normal vision) to 28 (very low vision). Blindness or a Parinaud score higher than 4 (Snellen equivalent < 20/60) were classified as "moderate to severe visual impairment". "Mild visual impairment" was defined as a Parinaud score higher than 2 and less than or equal to 4 (Snellen equivalent [20/60-20/30[) and "no visual impairment" as a Parinaud score of 
2 or less (Snellen equivalent $\geq 20 / 30$ ). Decline was defined as at least a one point increase on the Parinaud scale between baseline and 2 year measures.

Distance visual function was self-reported during a face to face interview, and functional loss was defined as inability or difficulty in recognizing a face at 4 meters. Subjects switching between inclusion and 2-year examination from "without difficulties" to at least "with difficulties" or from "with difficulties" to "unable" were classified as having a decline in distance visual function.

\section{Socio-demographic and clinical variables}

The standardized interview included questions about demographic characteristics: education level (classified in four groups corresponding to 5, 9, 12, and 13+ years of education), low income ( $\leq$ $1500 € /$ month), marital status, mode of living (alone or not), questions about mobility (restricted to bed or home or neighborhood), falls during the last months, diet (fruit and vegetable consumption), as well as an inventory of all drugs used over the preceding month. Information was also obtained on alcohol consumption (number of units of alcohol per day; $0,1-36,>36 \mathrm{~g} /$ day), tobacco use (classified as past, present or never users). Standardized medical questionnaire included history of stroke, angina pectoris, myocardial infarction, and cardio-vascular surgery, cancer (during the two last years), asthma (attacks during the last year), and chronic bronchitis. Medical examination included measures of height, and weight [body mass index (BMI) classified as normal: BMI, less than 25; overweight: BMI, 25-29.9; obesity: BMI of 30 or greater] and screened for hypertension (>160/95 mm Hg or treated) and diabetes (fasting glycemia $>7 \mathrm{mmol} / \mathrm{l}$ or treated). Blood pressure was measured using a digital electronic tensiometer OMRON M4. Cognitive impairment was defined as an Isaacs test score (Isaacs and Kennie, 1973) lower than 38 corresponding to the first quartile (test of verbal recall and fluency without visual items and being sensitive to lesions in most cortical areas).Venous blood samples were taken at baseline after fasting for $>12 \mathrm{~h}$. Lipid levels 
including HDL cholesterol were evaluated in serum and APOE genotyping was performed as previously described (Ancelin et al., 2010), $\varepsilon 4$ allele having been found to be protective of ocular diseases (Baird et al., 2004; Utheim et al., 2008).

\section{Statistical analyses}

The effect of baseline vision loss on 10-year incident depressive symptomatology or of baseline depressive symptomatology on 10-year incident vision loss were analyzed using a mixed logistic model (Carriere and Bouyer, 2002) which takes into account within-subject response correlation (dependency between repeated evaluations) and models the individual repeated probabilities of the outcome during the 10-year follow-up. Briefly, this model has four basic characteristics: (i) the individual time evolutions of the outcome are entirely taken into account including possible reversion to normal state, (ii) subjects with incomplete responses across time are included in the analysis, (iii) subjects do not have to be evaluated at the same time points, (iv) the model allows within-subject dependency to vary from one subject to another, via the random part of the covariable linear combination. "Baseline" refers to the condition at inclusion. The SAS procedure NLMIXED was used to estimate the parameters (version 9.2).

We used three adjusted models. In model 0 , odds ratios (OR) were adjusted for centre, gender, age and time. In addition, model 1 included covariates that were associated with the follow-up outcomes ( $\mathrm{p}<0.10$ in model 0$)$. Model 2 was further adjusted for covariates which may also be intermediate factors and thus may yield an over-adjusted model. In the incidence of depressive symptomatology sub-study, model 1 was thus adjusted for age, centre, gender, time, income, living alone, ischemic pathologies, diabetes, respiratory diseases, number of medications and obesity. Model 2 was further adjusted for mobility, cognitive impairment and falls. In the incidence of visual impairment and of visual function loss sub-studies, model 1 was adjusted for age, centre, 
gender, time, income, living alone, hypertension, diabetes, respiratory diseases, number of medications, obesity, ApoEc4, HDL cholesterol, and fruit and vegetable consumption. Model 2 was further adjusted for mobility and cognitive impairment.

\section{RESULTS}

For the total sample of 4216 dementia-free participants at baseline, median (IQR) age was 73 (7077) and $40.2 \%$ were men. The prevalence of depressive symptomatology was $24.3 \%$ and $7.6 \%$ of the whole cohort were treated with antidepressants. Regarding vision, $11.2 \%$ had mild near visual impairment, $2.7 \%$ moderate to severe near visual impairment (among them 7 blind subjects $(0.2 \%)$ ) and $4.5 \%$ a loss of distance visual function. With regard to the associations between visual impairment and declared visual function, $83.9 \%$ had neither near visual impairment nor loss in distance visual function while $10.3 \%$ had mild and $1.4 \%$ moderate to severe near visual impairment, but not visual function loss. One percent had mild and $1.2 \%$ moderate to severe near visual impairment associated with a visual function loss.

\section{Incidence of depressive symptomatology}

For the incidence of depressive symptomatology analysis, participants free of depressive symptomatology and not treated with antidepressants at baseline were included in the analysis. The sample of 2307 subjects is described in Table 1. Median (IQR) time of follow-up was 9.0 years (6.9-9.5). In this sub-sample, with regard to near visual acuity, $9.8 \%$ of the participants had mild visual impairment and $2.0 \%$ moderate to severe impairment at baseline. The baseline prevalence of loss of distance visual function was $3.2 \%$.

Over the 10 years follow-up, 521 persons (22.6\%) reported incident depressive symptomatology (that is on at least one follow-up visit) with 280 participants $(53.7 \%)$ reverting to a non-depressed 
state on a subsequent visit. Rates of severe depression increased from $8.6 \%$ at 2 years to $11.8 \%$ at 10 years.

After adjustment for gender, centre, age and time, participants with mild near visual impairment at baseline increased their odds of developing depressive symptomatology (Model 0) compared to participants without any near visual impairment $(\mathrm{OR}=1.60 ; 95 \% \mathrm{CI}=1.08-2.38)$ (Table2). Further adjustment for socio-economic factors (income, living alone), and comorbidity (ischemic pathologies, diabetes, respiratory diseases number of medications and obesity) attenuated the associations (Model 1: $\mathrm{OR}=1.45 ; 95 \% \mathrm{CI}=0.98-2.15)$ which failed to be significant. The relationship was not significant for moderate to severe impairment and for the 2 -year decrease in near visual acuity in all models (data not shown).

With regard to distance visual function, baseline loss was not associated with the odds of developing depressive symptomatology. On the other hand a 2-year decrease in distance visual function was associated with increased odds of depressive symptomatology during follow-up (Table 2). The relationship remained highly significant in models 1 and model 2 (OR=3.03; $95 \%$ $\mathrm{CI}=1.75-5.23)$ and also when past $\mathrm{MDE}$ was entered in the model $(\mathrm{OR}=2.90 ; 95 \% \mathrm{CI}=1.68-4.99$, $\mathrm{p}=0.0001)$.

\section{Incidence of near visual impairment}

Participants with normal near visual acuity at baseline were included in this analysis. The median (IQR) time of follow-up was 8.9 years (6.8-9.4). Of the 2760 subjects included, $21.6 \%$ had depressive symptomatology at baseline, $6.5 \%$ were treated with antidepressants and $16.6 \%$ had a history of MDE (Table 1). Over the 10-year follow-up, 668 persons (24.2\%) had incident near visual impairment (at least one follow-up visit with mild to severe visual impairment) and the reversibility rate was $33.8 \%$. The rate of near vision impairment was of 5.5\%, 7.2\%, 7.8\% and 
$21.0 \%$ at 2 years, 4 years, 7 years and 10 years respectively, the rise at 10 years being partially due to cohort aging (participants aged 85 years and over represented 5\% of the sample at 2 years but $25 \%$ after 10 years).

Adjusted for centre, gender, age and time, baseline depressive symptomatology was weakly associated with an increased odds of developing near visual impairment $(\mathrm{OR}=1.26 ; 95 \% \mathrm{CI}=1.00$ 1.60) (Model 0) but the association disappeared after multiple adjustment (Models 1 and 2)

(Table 3).

\section{Incidence of distance visual function loss}

Participants having difficulties in recognizing a face at 4 meters at baseline were excluded from this separate analysis. The median (IQR) period of follow-up was 9.0 years (6.7-9.5). The baseline rates for current depressive symptomatology, past MDE and antidepressant use were similar to the near visual impairment sub-study (Table 1). Over the 10-year follow-up, 321 (10.9\%) participants had incident loss of distance visual function with $57.0 \%$ reverting to a normal state. The rate of visual function loss remained stable over time and varied from $3.9 \%$ at 2 years, to $5.0 \%$ at 10 years.

After adjustment for centre, gender, age and time, baseline depressive symptomatology was associated with a loss in distance visual function during follow-up ( $\mathrm{OR}=1.72 ; 95 \% \mathrm{CI}=1.23-2.42)$ (Model 0). The association remained significant after further adjustment for socio-economic factors (income, living alone), comorbidity (ischemic pathologies, diabetes, respiratory diseases number of medications and obesity), ApoEc4, HDL cholesterol and fruit and vegetable consumption (Model 1) as well as mobility and cognitive impairment ( $\mathrm{OR}=1.62 ; 95 \% \mathrm{CI}=1.15-2.28)$ (Model 2) (Table 3). When baseline antidepressant use and history of MDE were added to model 2 the association remained unchanged $(\mathrm{OR}=1.58 ; 95 \% \mathrm{CI}=1.11-2.25, \mathrm{p}=0.01)$. 


\section{DISCUSSION}

Previous research has pointed to a general association between vision loss and the subsequent onset of depressive symptomatology. However, the results of the present analyses suggest that this relationship is complex depending on whether the loss is related to near visual impairment or visual function loss and visual decline across time. We observed depressive symptomatology onset to be specifically related to a recent decrease (in the last two years) in distance visual function, increasing three-fold the risk of developing depressive symptomatology in the following years. Mild near visual impairment (but not recent decline) increased the risk for incident depressive symptomatology; however, this association did not quite reach significance after multivariate adjustment. Of particular interest are our novel findings related to reverse causality. A strong association was observed between depressive symptomatology at baseline and incidence of visual function loss, even after multiple adjustments for potential confounders, the odds of having a visual function loss increasing by $62 \%$ over 10 years. Depressive symptomatology at baseline was however, not associated with incident near visual impairment.

Vision loss as a risk factor for depressive symptomatology

There are multiple inter-related mechanisms by which visual impairments may increase vulnerability to depression, notably through loss of independence for daily living activities, difficulties in maintaining social networks, leisure activities and adequate health care, as well as loneliness, poor diet, and loss of self-confidence due to fears of falling and further vision loss. Progressive adaptation in performing daily living tasks is possible despite insidious visual decline, such that the person may not be aware of their real level of sensory deficiency. Unrecognized impairment may thus create over time an accumulation of activity restrictions, dependency and feelings of frustration (Vu et al., 2005) leading subsequently to depression. Longitudinal studies 
such as ours permit the exploration of the delayed effect of vision loss, and measuring near visual acuity has the additional advantage of including unrecognized (and thus uncorrected) deficiencies.

Two previous population-based longitudinal studies (Brown and Barrett, 2011; Chou, 2008) investigating specifically the effect of global vision loss on depressive symptoms found a positive association. In two-wave studies, the authors used a self-reported categorical assessment of global visual function with usual optical correction. Brown et al. (Brown and Barrett, 2011) did not exclude from the analysis participants presenting depressive symptoms at baseline, thus confounding the effects of baseline depression and baseline vision. However, by investigating possible mediating effects they observed that "psychological resources" (self-efficacy) and activity limitations to be two principal mediators. Chou et al. (Chou, 2008) showed that self-assessed visual function was associated with onset and persistence of depressive symptoms, and that mobility and instrumental activities of daily living (IADL) partially mediated this relationship. Another population-based study examined the effect of self-reported dual sensory loss (hearing and visual loss) without distinction of modality (McDonnall, 2009, 2011). A significant increase in depressive symptoms was observed at the first follow-up where sensory loss was reported and also over the subsequent examinations. The linear mixed model used in this analysis measured in fact the time by time short-term effect of sensory loss on the trajectory of depressive symptoms. This method may be subject to reciprocal causality (Neuhaus and Kalbfleisch, 1998) as depression may influence future measures of visual function leading to an over estimation of its effect. To overcome this methodological pitfall, we preferred to consider vision loss at baseline in subjects without depressive symptomatology. Several other longitudinal studies included visual function loss in overall analyses of risk factors for depressive symptom incidence, finding a positive (de Beurs et al., 2001; Forsell, 2000; Harris et al., 2006; Kennedy et al., 1990) or a non-significant 
association (Biderman et al., 2002; Prince et al., 1998).Visual functioning was always selfdeclared, often not precisely defined and only taken at baseline.

With regard to the change in distance visual function, the 2-year decrease was strongly associated with depressive symptomatology incidence, but baseline distance visual function was not. As distance vision was self-reported, the question remains as to whether this association is due to effective visual impairment or an over-declaration in people with a tendency to recurrent depression. The relationship persists, however, after adding past MDE to the final model. This observation suggests that a recent decrease in visual function may be more important in relation to depressive symptomatology than a sustained moderately low level, in the same way that Grue et al. (Grue et al., 2010) observed recent decline rather than stable impairment led to IADL impairment and declining social activity.

With regard to visual impairment, our study is the first to use an objective evaluation of near visual acuity in relation to depressive symptomatology, excluding depressed subjects at inclusion and with a long-term follow-up. We were also able to adjust for a large number of possible confounders. Only a slight association was found for mild near visual impairment with the incidence of depressive symptomatology. The absence of association for moderate to severe impairment is probably due to a lack of power, only $2 \%$ of subjects being in this category at baseline. In a population-based longitudinal study, Tournier et al. (Tournier et al., 2008) used a medical services data-base with International Classification of Diseases (ICD-9) algorithms, showing that over a 5-year period the risk of depression was higher in the group of subjects with objective visual impairment compared with the control group, and that the effect did not depend on visual impairment severity. However, in this study, the models were poorly adjusted without including socio-economic and behavioral factors or comorbidity, and only adjusting for chronic 
diseases as a single score. In a large cross-sectional nationally representative sample of US adults (Zhang et al., 2013) (23\% of participants $\geq 65$ years) visual function loss was also associated with depression after multiple adjustment but visual acuity was not. Impairment of optical organs may have effects on visual acuity but also on contrast sensitivity (Alexander et al., 1988) and visual field. Self-reported visual function loss has the advantage of covering global effects on daily activities.

Several randomized clinical trials have been undertaken based on the assumption of a causal relationship between visual impairment and depression, but almost exclusively in nursing homes where the rate of age-related eye disease and under-corrected refractive error is high. Owsley et al showed, for example, that immediate refractive error correction reduced depression in comparison with delayed correction (Owsley et al., 2007a). However, in the same population, cataract surgery did not appear to have a similar effect (Owsley et al., 2007b). Age-related macular degeneration has also previously been demonstrated to be associated with high rates of depression, anxiety and emotional distress (Berman and Brodaty, 2006) and in a randomized controlled clinical trial that compared the efficacy of problem-solving treatment with usual care in patients, treatment of depression was found to be effective in the short-term but the benefits were not maintained over time (Rovner et al., 2007). The impact of visual impairment on depression may depend on the severity and the origin of visual impairment and the duration of visual loss.

\section{Depression as a risk factor for loss of vision}

Over time the effect of visual impairment on depression may be amplified by the effect of depression on vision. To our knowledge no previous population-based longitudinal study has investigated the question of possible bi-directionality. After adjusting for a large number of possible confounders including socio-demographic factors (age, gender, income, mode of living), 
concomitant pathologies (hypertension, diabetes, respiratory diseases, number of medications), biological factors (HDL cholesterol), behavioral factors (obesity, diet) and genetic (Apos4) and possible mediating factors (mobility, cognitive impairment) as well as antidepressant use and history of MDE, we found an independent association with the incidence of visual function loss. This suggests a highly significant impact on visual function whereas non-significant associations were found for incident near visual impairment after adjusting for behavioral and physical health confounders. In accordance with this result Rovner et al also showed in a small sample of 51 older patients with recent onset of bilateral AMD (Rovner et al., 2002), that change in depressive symptoms was correlated with concomitant change in vision function. However, the correlation with change in visual acuity was not significant.

We have suggested above several mechanisms to explain this association related to poor self-care and health behaviors, medication-related risks and possible neurophysiological pathways. Within our study we observed that 70 persons $(1.7 \%)$ were taking tricyclic antidepressants at base-line, which are known to promote interference in the accommodation process and can provoke angleclosure glaucoma in patients with narrow-angled eyes. Selective serotonin reuptake inhibitors (SSRIs) (4.3\% of participants in our study) have also been associated with mydriatic events which may increase susceptibility to glaucoma (Richa and Yazbek, 2010). We also postulated the possibility of a direct effect on neurotransmitter dysfunction present in depressive disorder, notably dopamine which is present in both amacrine and interplexiform cells, with alterations in dopaminergic neurotransmission possibly reducing contrast discrimination in depressive patients (Bubl et al., 2009). Dysfunction of the inhibitory neurotransmitter GABA may also have negative effects on the visual system in general (Golomb et al., 2009). However the role of neurotransmitters in explaining vision loss in elderly persons with depression may be modest in 
comparison with the behavioral consequences of depressive disorders (including postponed cataract surgery, lack of compliance with clinical recommendations and treatment and poor response to rehabilitation (Grant et al., 2011)).

\section{Clinical implications}

With regard to public health prevention and clinical practice in psychiatry our findings highlight the importance of detecting visual impairment in depressed elderly patients. Moreover measures of functional vision and their changes over time seem to be more informative than measures of acuity with regard to impact of vision loss on activities of daily living (Morse, 2013). Both dealing with vision loss and treating depression should be considered (Margrain et al., 2012). In general practice, attention to risk factors such as female gender, prior depression, disability, sleep disturbance, recent bereavement, and onset of co-pathologies (Cole and Dendukuri, 2003) could also permit early identification of persons with visual deficiencies at high risk of depression.

\section{Limitations and strength}

Our study was subject to several limitations. Functional vision was measured crudely and the level of visual function loss declared by the participant may have been over-estimated in depressed subjects, although the association persisted after multiple adjustments. Our measure of visual function (4 meter facial recognition) may only reflect central vision loss but not detect individuals with loss in peripheral vision (tunnel vision caused by glaucoma or retinal degeneration outside the macula) which is involved in vision-related tasks such as driving and shopping. Ocular conditions underlying the visual impairment were not recorded, so we were unable to differentiate correctable and non-correctable defects in relation to depression. A selection bias is also possible as people with low vision or major depression may have refused to participate. 
However the present prospective study with a multicentre design, based on a large community sample has allowed us to examine separately distance visual function and near visual impairment and evaluate for the first time the long-term bidirectional association between measured near visual acuity and depressive symptomatology. Visual acuity was measured with the usual optical correction according to WHO recommendations. For detection of depressive symptomatology we used both a clinical interview designed to detect major depression and the 20-item CES-D scale designed for nonclinical samples such as that of this study. We adjusted the statistical models for a wide range of possible confounders and mediators, including lifestyle and comorbidity.

The nature of the causal association between vision loss and depressive symptomatology is difficult to assess without repeated ophthalmologic examinations and a repeated evaluation of clinical depression. Introducing standard visual examinations within population-based psychiatric cohort studies would provide this data. As depression and visual impairment are two frequently inter-related and incapacitating conditions that are often treatable, better detection of persons at risk and improved management may substantially improve the quality of life of the elderly. 


\section{ACKNOWLEDGMENTS}

Financial support: The 3C Study is conducted under a partnership agreement between the Institut National de la Santé et de la Recherche Médicale (Inserm), Victor-Segalen Bordeaux2 University, and Sanofi- Aventis. The 3C-Study was also supported by the Caisse Nationale Maladie des Travailleurs Salariés, Direction Générale de la Santé, MGEN, the Institut de la Longévité, Agence Française de Sécurité Sanitaire des Produits de Santé, the Regional Governments of Aquitaine, Bourgogne and Languedoc-Roussillon, the Fondation de France, the Ministry of Research-Inserm Programme 'Cohorts and collection of biological material', the "ANR - Agence Nationale de la Recherche - The French National Research Agency" under the "Programme National de Recherche en Alimentation et nutrition humaine", project "COGINUT ANR-06-PNRA-005", the "Programme Longévité et vieillissement", project 07-LVIE-004" and 07-LVIE 003 01, the Institut de Recherche en Santé Publique (IReSP), Paris, France and Novartis. The Lille Genopole was supported by an unconditional grant from Eisai.

This work was carried out with the financial support of the "ANR - Agence Nationale de la Recherche - The French National Research Agency" under the "Programme de Recherche en Santé Publique”, project 2010-PRSP-011.

Role of funding source: The funders had no role in the design and conduct of the study, collection, management, analysis, and interpretation of the data; and preparation, review, or approval of the manuscript.

\section{Conflict of interest: None}


Contributions to authors: Design of the study (IC, CD, KR), preparation of the manuscript (IC, MLA, KR), data collection and obtaining funding (IC, CD, KP, CB, KR), analysis of the data (IC), review and approval of the manuscript (IC, CD, VD, KP, CB, CF, MLA, KR). 


\section{References}

Alexander, M.F., Maguire, M.G., Lietman, T.M., Snyder, J.R., Elman, M.J., Fine, S.L., 1988. Assessment of visual function in patients with age-related macular degeneration and low visual acuity. Archives of ophthalmology 106, 1543-1547.

Ancelin, M.L., Carriere, I., Boulenger, J.P., Malafosse, A., Stewart, R., Cristol, J.P., Ritchie, K., Chaudieu, I., Dupuy, A.M., 2010. Gender and genotype modulation of the association between lipid levels and depressive symptomatology in community-dwelling elderly (the ESPRIT study). Biological psychiatry 68, 125-132.

Baird, P.N., Guida, E., Chu, D.T., Vu, H.T., Guymer, R.H., 2004. The epsilon2 and epsilon4 alleles of the apolipoprotein gene are associated with age-related macular degeneration. Investigative ophthalmology \& visual science 45, 1311-1315.

Berger, S., Porell, F., 2008. The association between low vision and function. Journal of aging and health 20, 504-525.

Berman, K., Brodaty, H., 2006. Psychosocial effects of age-related macular degeneration. Int Psychogeriatr 18, 415-428.

Bernabei, V., Morini, V., Moretti, F., Marchiori, A., Ferrari, B., Dalmonte, E., De Ronchi, D., Rita Atti, A., 2011. Vision and hearing impairments are associated with depressive--anxiety syndrome in Italian elderly. Aging Ment Health 15, 467-474.

Biderman, A., Cwikel, J., Fried, A.V., Galinsky, D., 2002. Depression and falls among community dwelling elderly people: a search for common risk factors. J Epidemiol Community Health 56, 631-636.

Brown, R.L., Barrett, A.E., 2011. Visual impairment and quality of life among older adults: an examination of explanations for the relationship. The journals of gerontology 66, 364-373.

Bubl, E., Tebartz Van Elst, L., Gondan, M., Ebert, D., Greenlee, M.W., 2009. Vision in depressive disorder. World J Biol Psychiatry 10, 377-384.

Carriere, I., Bouyer, J., 2002. Choosing marginal or random-effects models for longitudinal binary responses: application to self-reported disability among older persons. BMC Med Res Methodol 2, 15.

Chou, K.L., 2008. Combined effect of vision and hearing impairment on depression in older adults: evidence from the English Longitudinal Study of Ageing. Journal of affective disorders 106, 191196.

Cole, M.G., Dendukuri, N., 2003. Risk factors for depression among elderly community subjects: a systematic review and meta-analysis. Am J Psychiatry 160, 1147-1156.

de Beurs, E., Beekman, A., Geerlings, S., Deeg, D., Van Dyck, R., Van Tilburg, W., 2001. On becoming depressed or anxious in late life: similar vulnerability factors but different effects of stressful life events. Br J Psychiatry 179, 426-431.

Evans, J.R., Fletcher, A.E., Wormald, R.P., 2007. Depression and anxiety in visually impaired older people. Ophthalmology 114, 283-288.

Forsell, Y., 2000. Predictors for Depression, Anxiety and psychotic symptoms in a very elderly population: data from a 3-year follow-up study. Soc Psychiatry Psychiatr Epidemiol 35, 259-263. Glynn, R.J., Rosner, B., Christen, W.G., 2009. Evaluation of risk factors for cataract types in a competing risks framework. Ophthalmic epidemiology 16, 98-106.

Golomb, J.D., McDavitt, J.R., Ruf, B.M., Chen, J.I., Saricicek, A., Maloney, K.H., Hu, J., Chun, M.M., Bhagwagar, Z., 2009. Enhanced visual motion perception in major depressive disorder. J Neurosci 29, 9072-9077. 
Grant, P., Seiple, W., Szlyk, J.P., 2011. Effect of depression on actual and perceived effects of reading rehabilitation for people with central vision loss. J Rehabil Res Dev 48, 1101-1108.

Grue, E.V., Finne-Soveri, H., Stolee, P., Poss, J., Sorbye, L.W., Noro, A., Hirdes, J.P., Ranhoff, A.H., 2010. Recent visual decline-a health hazard with consequences for social life: a study of home care clients in 12 countries. Curr Gerontol Geriatr Res.

Harris, T., Cook, D.G., Victor, C., DeWilde, S., Beighton, C., 2006. Onset and persistence of depression in older people--results from a 2-year community follow-up study. Age Ageing 35, 2532.

Heikkinen, R.L., Kauppinen, M., 2004. Depressive symptoms in late life: a 10-year follow-up. Arch Gerontol Geriatr 38, 239-250.

Isaacs, B., Kennie, A.T., 1973. The Set test as an aid to the detection of dementia in old people. $\mathrm{Br}$ J Psychiatry 123, 467-470.

Jacobs, J.M., Hammerman-Rozenberg, R., Maaravi, Y., Cohen, A., Stessman, J., 2005. The impact of visual impairment on health, function and mortality. Aging Clin Exp Res 17, 281-286.

Kennedy, G.J., Kelman, H.R., Thomas, C., 1990. The emergence of depressive symptoms in late life: the importance of declining health and increasing disability. Journal of community health 15 , 93-104.

Laitinen, A., Sainio, P., Koskinen, S., Rudanko, S.L., Laatikainen, L., Aromaa, A., 2007. The association between visual acuity and functional limitations: findings from a nationally representative population survey. Ophthalmic epidemiology 14, 333-342.

Lam, B.L., Christ, S.L., Lee, D.J., Zheng, D.D., Arheart, K.L., 2008. Reported visual impairment and risk of suicide: the 1986-1996 national health interview surveys. Archives of ophthalmology 126, 975-980.

Margrain, T.H., Nollett, C., Shearn, J., Stanford, M., Edwards, R.T., Ryan, B., Bunce, C., Casten, R., Hegel, M.T., Smith, D.J., 2012. The Depression in Visual Impairment Trial (DEPVIT): trial design and protocol. BMC Psychiatry 12, 57.

McDonnall, M.C., 2009. The effects of developing a dual sensory loss on depression in older adults: a longitudinal study. Journal of aging and health 21, 1179-1199.

McDonnall, M.C., 2011. Physical status as a moderator of depressive symptoms among older adults with dual sensory loss. Rehabilitation psychology 56, 67-76.

Morse, A.R., 2013. Vision Function, Functional Vision, and Depression. JAMA Ophthalmol, 1-2. Neuhaus, J.M., Kalbfleisch, J.D., 1998. Between- and within-cluster covariate effects in the analysis of clustered data. Biometrics 54, 638-645.

Owsley, C., McGwin, G., Jr., Scilley, K., Meek, G.C., Seker, D., Dyer, A., 2007a. Effect of refractive error correction on health-related quality of life and depression in older nursing home residents. Archives of ophthalmology 125, 1471-1477.

Owsley, C., McGwin, G., Jr., Scilley, K., Meek, G.C., Seker, D., Dyer, A., 2007b. Impact of cataract surgery on health-related quality of life in nursing home residents. The British journal of ophthalmology 91, 1359-1363.

Pascolini, D., Mariotti, S.P., 2012. Global estimates of visual impairment: 2010. The British journal of ophthalmology 96, 614-618.

Prince, M.J., Harwood, R.H., Thomas, A., Mann, A.H., 1998. A prospective population-based cohort study of the effects of disablement and social milieu on the onset and maintenance of latelife depression. The Gospel Oak Project VII. Psychological medicine 28, 337-350.

Radloff, L., 1977. The CES-D scale: a self-report depression scale for research in the general population. Appl Psychol Meas 1, 385-401. 
Richa, S., Yazbek, J.C., 2010. Ocular adverse effects of common psychotropic agents: a review. CNS Drugs 24, 501-526.

Rovner, B.W., Casten, R.J., Hegel, M.T., Leiby, B.E., Tasman, W.S., 2007. Preventing depression in age-related macular degeneration. Arch Gen Psychiatry 64, 886-892.

Rovner, B.W., Casten, R.J., Tasman, W.S., 2002. Effect of depression on vision function in agerelated macular degeneration. Archives of ophthalmology 120, 1041-1044.

Sheehan, D.V., Lecrubier, Y., Sheehan, K.H., Amorim, P., Janavs, J., Weiller, E., Hergueta, T., Baker, R., Dunbar, G.C., 1998. The Mini-International Neuropsychiatric Interview (M.I.N.I.): the development and validation of a structured diagnostic psychiatric interview for DSM-IV and ICD10. J Clin Psychiatry 59 Suppl 20, 22-33.

The 3C Study Group, 2003. Vascular factors and risk of dementia: Design of the three city study and baseline characteristics of the study population. Neuroepidemiology 22, 316-325.

Tournier, M., Moride, Y., Ducruet, T., Moshyk, A., Rochon, S., 2008. Depression and mortality in the visually-impaired, community-dwelling, elderly population of Quebec. Acta Ophthalmol 86, 196-201.

Utheim, O.A., Ritland, J.S., Utheim, T.P., Espeseth, T., Lydersen, S., Rootwelt, H., Semb, S.O., Elsas, T., 2008. Apolipoprotein E genotype and risk for development of cataract and age-related macular degeneration. Acta Ophthalmol 86, 401-403.

Vu, H.T., Keeffe, J.E., McCarty, C.A., Taylor, H.R., 2005. Impact of unilateral and bilateral vision loss on quality of life. The British journal of ophthalmology 89, 360-363.

Waern, M., Rubenowitz, E., Runeson, B., Skoog, I., Wilhelmson, K., Allebeck, P., 2002. Burden of illness and suicide in elderly people: case-control study. BMJ 324, 1355.

World Health Organisation, 2006. List of Official ICD-10 Updates. ICD-10 Updates 2006. Ratified October 2006. http://www.who.int/classifications/icd/icd10updates/en/index.html.

Zhang, X., Bullard, K.M., Cotch, M.F., Wilson, M.R., Rovner, B.W., McGwin, G., Owsley, C., Barker, L., Crews, J.E., Saaddine, J.B., 2013. Association Between Depression and Functional Vision Loss in Persons 20 Years of Age or Older in the United States, NHANES 2005-2008. JAMA Ophthalmol, 1-9. 
Table 1. Description at baseline of the three sub-samples examining incidence of depressive symptomatology, near visual impairment and visual function loss.

\begin{tabular}{|c|c|c|c|}
\hline & $\begin{array}{c}\text { Incidence of depressive } \\
\text { symptomatology sub-study: } \\
\text { Participants free of } \\
\text { depressive symptomatology } \\
\text { and not treated at baseline } \\
(\mathrm{N}=2307) \\
\%\end{array}$ & $\begin{array}{c}\text { Incidence of near visual } \\
\text { impairment sub-study: } \\
\text { Participants free of near } \\
\text { visual impairment at } \\
\text { baseline } \\
(\mathrm{N}=2760) \\
\%\end{array}$ & $\begin{array}{l}\text { Incidence of visual function } \\
\text { loss sub-study: } \\
\text { Participants free of loss in } \\
\text { distance visual function at } \\
\text { baseline } \\
(\mathrm{N}=2952) \\
\%\end{array}$ \\
\hline Sex (male) & 45.7 & 41.8 & 41.3 \\
\hline \multicolumn{4}{|l|}{ Age } \\
\hline 65-69 & 27.6 & 28.3 & 27.0 \\
\hline $70-74$ & 35.6 & 36.2 & 35.7 \\
\hline $75-80$ & 24.5 & 24.3 & 25.3 \\
\hline $80+$ & 12.3 & 11.2 & 12.0 \\
\hline Education $(\leq 5$ years $)$ & 27.2 & 25.9 & 27.7 \\
\hline Income $(\leq 1500 € /$ month $)$ & 29.8 & 30.1 & 31.8 \\
\hline Living alone & 27.4 & 29.2 & 30.7 \\
\hline Hypertension & 51.4 & 49.7 & 50.5 \\
\hline Ischemic pathologies & 15.2 & 14.4 & 15.0 \\
\hline Diabetes & 9.6 & 8.8 & 9.4 \\
\hline
\end{tabular}


Respiratory diseases

Number of drugs

Less than 3

3-5

6 or more

BMI

Normal $(<25)$

Overweight (25-29)

Obese $(\geq 30)$

3 times or more/day

Near visual impairment at baseline

No impairment

Mild

Moderate to severe
35.3

42.1

\section{2}

9.8

46.9 
Two-year decrease in near visual acuity

Distance visual function loss at baseline

Two-year decrease in distance visual function Depressive symptomatology

Antidepressant

History of major depressive episode
5.3

3.2

3.6

21.6

6.5

(20.6

6.7

11.2

16.6 
Table 2. Near visual impairment and visual function loss as risk factors for incident depressive symptomatology

\begin{tabular}{|c|c|c|c|c|c|c|}
\hline & \multicolumn{2}{|c|}{ Model $0^{\mathrm{a}}$} & \multicolumn{2}{|c|}{ Model $1^{\mathrm{b}}$} & \multicolumn{2}{|c|}{ Model $2^{c}$} \\
\hline & OR $(95 \% \mathrm{CI})$ & p-value & OR $(95 \% \mathrm{CI})$ & p-value & OR $(95 \% \mathrm{CI})$ & p-value \\
\hline \multicolumn{7}{|l|}{ Near visual impairment ( $\mathrm{n}=2307$ ) } \\
\hline Baseline mild visual impairment & $1.60(1.08-2.38)$ & 0.02 & $1.45(0.98 ; 2.15)$ & 0.06 & $1.41(0.95-2.09)$ & 0.08 \\
\hline Baseline moderate to severe visual & $0.79(0.32-1.94)$ & 0.61 & $0.59(0.24-1.42)$ & 0.24 & $0.55(0.22-1.35)$ & 0.19 \\
\hline \multicolumn{7}{|l|}{ impairment } \\
\hline \multicolumn{7}{|l|}{ Distance visual function $(\mathrm{n}=2193)^{\mathrm{d}}$} \\
\hline Baseline visual function loss & $0.77(0.37-1.60)$ & 0.49 & $0.72(0.35-1.47)$ & 0.37 & $0.69(0.33-1.41)$ & 0.31 \\
\hline 2-year decrease in visual function & $3.18(1.81-5.59)$ & $<0.0001$ & $3.03(1.75-5.24)$ & $<0.0001$ & $3.03(1.75-5.23)$ & $<0.0001$ \\
\hline
\end{tabular}

${ }^{\mathrm{a}}$ Model 0: adjusted for centre, baseline age, gender, time since baseline

${ }^{\mathrm{b}}$ Model 1: model $0+$ income, living alone, ischemic pathologies, diabetes, respiratory diseases, number of medications and obesity

${ }^{\mathrm{c}}$ Model 2: model $1+$ mobility, cognitive impairment and falls

${ }^{\mathrm{d}} \mathrm{n}=114$ without evaluation of distance visual function at 2 years. 
Table 3. Depressive symptomatology as a risk factor for incident visual impairment and visual function loss

\begin{tabular}{|c|c|c|c|c|c|c|}
\hline & OR $(95 \% \mathrm{CI})$ & p-value & OR $(95 \% \mathrm{CI})$ & $\mathrm{p}$-value & OR $(95 \% \mathrm{CI})$ & $\mathrm{p}$-value \\
\hline \multicolumn{7}{|l|}{$\begin{array}{l}\text { Incidence of near visual impairment } \\
(n=2760)\end{array}$} \\
\hline \multicolumn{7}{|l|}{$\begin{array}{l}\text { Incidence of distance visual function loss } \\
(\mathrm{n}=2952)\end{array}$} \\
\hline & $1.72[1.23-2.42]$ & 0.002 & $1.65[1.17-2.32]$ & 0.005 & $1.62[1.15-2.28]$ & 0.006 \\
\hline
\end{tabular}

\footnotetext{
${ }^{\mathrm{a}}$ Model 0: adjusted for centre, baseline age, gender, time since baseline

${ }^{\mathrm{b}}$ Model 1: model 0 + income, living alone, hypertension, diabetes, respiratory diseases, number of medications, obesity, APOE 4 , HDL, fruit and vegetable consumption,

${ }^{\mathrm{c}}$ Model 2: model $1+$ mobility and cognitive impairment
} 